\title{
Studies on the Polymerization of Acrolein Oxime. V. Cationic Polymerization
}

\author{
Seizo Masuda and Tadatoshi OTA \\ Department of Applied Chemistry, Faculty of Engineering, \\ Tokushima University, Tokushima 770, Japan.
}

(Received September 16, 1977)

\begin{abstract}
The polymerization of acrolein oxime initiated by hydrochloric acid has been studied in 1, 2-dichloroethane solution over the temperature ranges from $0^{\circ}$ to $40^{\circ} \mathrm{C}$. The reaction is incomplete, giving limited yields of polymer, depending on the initial catalyst concentration, but not on that of the monomer. Consequently, individual values of the rate constants are estimated on the basis of the nonstationary chain reaction proposed by Pepper. The molecular weights of polymers obtained are very low $(<1000)$ and are determined by chain transfer rather than termination processes. The polymer consists of a few kinds of structural units, and of the corresponding reactions, the 1,2-addition is predominant.

KEY WORDS Acrolein Oxime/Cationic Polymerization/ Nonstationary State / Rate Constants / Structure of Polymer /
\end{abstract}

It has been reported ${ }^{1}$ that polymerization of acrolein oxime (AOM) can be initiated thermally, either by benzoyl peroxide, by $\gamma$-irradiation or by boron trifluoride ethyl etherate. The data presented in our previous paper ${ }^{2,3}$ have demonstrated that AOM is an efficient inhibitor of radical polymerizations, and the thermal polymerization of AOM itself follows an anionic mechanism.

It has been nevertheless concluded that AOM has the highest cationic polymerizability. This conclusion was drawn from the data of copolymerization of AOM $\left(\mathrm{M}_{1}\right)$ and styrene $\left(\mathrm{M}_{2}\right)$, where a hydrochloric acid catalyst gave values of $r_{1}=30$ and $r_{2}=0.01$, while $n$-butyllithium gave values of $r_{1}=9.8$ and $r_{2}=0^{2}$.

The polymerization of AOM by hydrochloric acid is incomplete, giving limited yields of polymer, depending on the initial acid concentration, but not on that of the monomer. Consequently, the rate constants for elementary reactions were estimated according to Pepper's equation. ${ }^{4}$

\section{EXPERIMENTAL}

\section{Materials}

AOM was prepared according to the method described in a previous paper; ${ }^{5}$ bp $44^{\circ} \mathrm{C}(14 \mathrm{~mm})$.
1, 2-Dichloroethane (DCE) and other agents were purified by the usual methods. Hydrochloric acid, a cationic catalyst, was of special grade reagent of Wako Chemical Industries Ltd., and used without further purification.

\section{Polymerization Procedure}

The desired amounts of both AOM and DCE were placed in a $50-\mathrm{m} l$ Erlenmeyer flask with a rubber stopper. This solution was cooled to $0^{\circ} \mathrm{C}$ in a ice bath, and concentrated hydrochloric acid was injected through the stopper. In the hydrogen chloride-catalyzed polymerization a similar procedure was used except for the use of DCE which took up the catalyst. After a given time, the catalytic amount of pyridine was added, and the contents were poured into a large amount of ether to precipitate the polymer. The rate of polymerization was gravimetrically determined.

\section{Characteristics of Poly(acrolein oxime) (PAOM)}

Molecular weights of PAOM were determined in aqueous solution at $40^{\circ} \mathrm{C}$ by a vapor-pressure osmometer (Hitachi Perkin-Elmer, model 115). The content of carbon-carbon double bond was calculated by determining the iodine value. ${ }^{6}$ The oxime group in PAOM was reduced to the primary amine with hydrogen in the presence of a 
Raney nickel catalyst, ${ }^{1}$ and the amount of the amine was then determined by the Van Slyke method. ${ }^{7}{ }^{1}$ NMR spectra of PAOM obtained were measured as described in a preceding paper. ${ }^{8}$

\section{RESULTS AND DISCUSSION}

\section{The Polymerization of AOM}

Water in general has an appreciable effect on ionic polymerizations. For the AOM polymerization, however, water is considered not to serve as an inhibitor. This consideration is based on the following facts: (1) The polymer is obtained as a by-product in the preparation of AOM monomer, (2) the thermal polymerization of AOM, which proceeds by an anionic mechanism, in aqueous solution is as fast as that in benzene solution, and (3) AOM containing trace amount of water as impurity undergoes cationic and anionic polymerizations by $\gamma$-irradiation, the rate being proportional to the square root of dose rate. ${ }^{9}$

Figures 1 and 2 show time-conversion curves for the polymerization at $0^{\circ} \mathrm{C}$ in the presence of hydrochloric acid or hydrogen chloride. As can be seen from Figure 2, a small amount of water has no influence on the rate of the polymeriza-

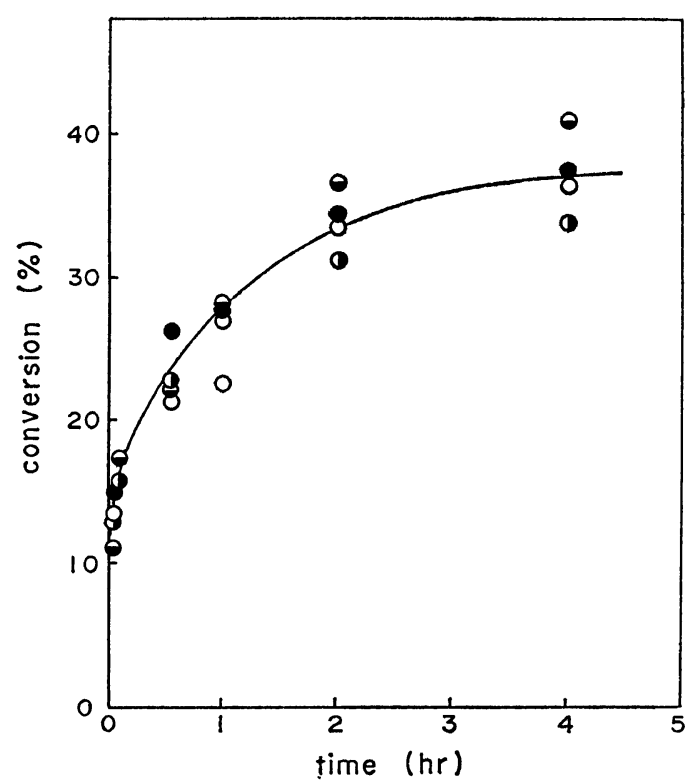

Figure 1. Time-conversion curve for AOM polymerization at $0^{\circ} \mathrm{C}$ with different concentrations of monomer: $[\mathrm{HCl}]=0.058 \mathrm{~mol} / l ;\left[\mathrm{H}_{2} \mathrm{O}\right]=0.218 \mathrm{~mol} / l$; $[\mathrm{AOM}]=10.84(\ominus), 8.13(\odot), 6.77(\mathrm{O})$, and $5.42(\bullet) \mathrm{mol} / \mathrm{l}$. tion. The reactions are initially extremely fast, but become gradually sluggish with time, and appear to come to a halt before all the monomer is consumed. Expressed as the logarithmic conversion function, $\ln \left\{\left(1 /\left(1-X_{\infty}\right)\right\}\right.$, the asymptotic conversions can be seen to be in direct proportion

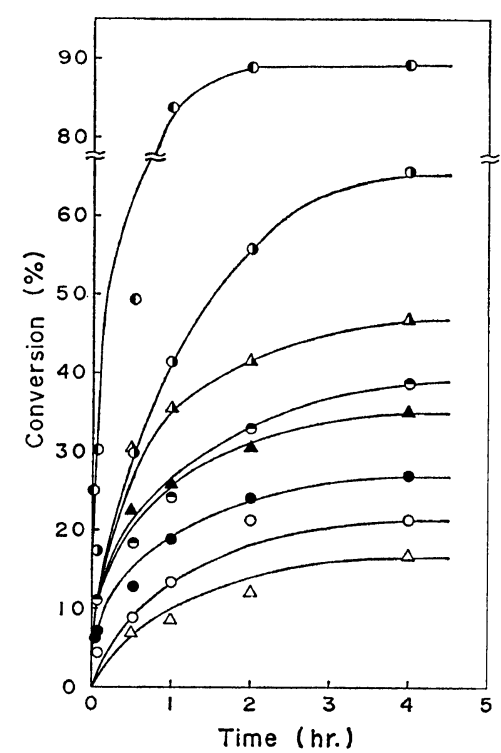

Figure 2. Time-conversion curves for AOM polymerization at $0^{\circ} \mathrm{C}$ with different concentrations of catalyst: $[\mathrm{AOM}]=6.77 \mathrm{~mol} / l ; 0,[\mathrm{HCl}]=0.232$, $\left[\mathrm{H}_{2} \mathrm{O}\right]=0.874 ; \circlearrowleft,[\mathrm{HCl}]=0.116,\left[\mathrm{H}_{2} \mathrm{O}\right]=0.437 ; \theta$, $[\mathrm{HCl}]=0.058,\left[\mathrm{H}_{2} \mathrm{O}\right]=0.218 ;$ ○. $[\mathrm{HCl}]=0.029,\left[\mathrm{H}_{2} \mathrm{O}\right]$ $=0.110 ; \mathrm{O},[\mathrm{HCl}]=0.0145,\left[\mathrm{H}_{2} \mathrm{O}\right]=0.0546 ; \Delta,[\mathrm{HCl}]$ $=0.075,\left[\mathrm{H}_{2} \mathrm{O}\right]=0 ; \Delta,[\mathrm{HCl}]=0.041,\left[\mathrm{H}_{2} \mathrm{O}\right]=0 ; \Delta$, $[\mathrm{HCl}]=0.016,\left[\mathrm{H}_{2} \mathrm{O}\right]=0 \mathrm{~mol} / l$.

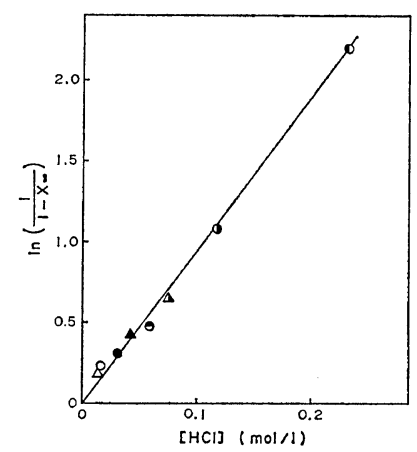

Figure 3. Relationship between the final conversion and the initial catalyst concentration. Marks correspond to those in Figure 2. [AOM] $=6.77 \mathrm{~mol} / l$; temp, $0^{\circ} \mathrm{C}$. 
to the catalyst concentrations (Figure 3). Similar results have been obtained in the polymerization of styrene $^{10}$ and its $p$-substituted derivatives ${ }^{11}$ in the presence of sulfuric acid, and the rate equation for them has been derived by Burton and Pepper ${ }^{4}$ using the assumption of a nonstationary state chain reaction having a very rapid initiation process and a first-order termination process.

Table I. Relationship between water added and molecular weight in hydrogen chloride-catalyzed polymerization of $\mathrm{AOM}^{\mathrm{a}}$

\begin{tabular}{lcc}
\hline $\begin{array}{c}{\left[\mathrm{H}_{2} \mathrm{O}\right],} \\
\mathrm{mol} / l\end{array}$ & $\begin{array}{c}\text { Yield of } \\
\text { polymer, \% }\end{array}$ & $\begin{array}{c}\text { Molecular } \\
\text { weight }\end{array}$ \\
\hline 0 & 47.05 & 540 \\
0.058 & 47.17 & 576 \\
0.107 & 44.60 & 512 \\
0.161 & 46.65 & 552 \\
0.222 & 44.60 & 535 \\
\hline
\end{tabular}

a This polymerization was carried out at $0^{\circ} \mathrm{C}$ for $4 \mathrm{hr}$ with $[\mathrm{AOM}]=6.77 \mathrm{~mol} / l$ and $[\mathrm{HCl}]=0.075 \mathrm{~mol} / l$.

The fact that the molecular weight of the resulting PAOM is very low indicates that the chaintransfer reaction occurs frequently. As can be seen from Table I, the molecular weight of PAOM is independent of the water added, and hence the chain transfer to water can be negligible. Therefore, assuming only the chain transfer to the monomer, Pepper's equation may be written as follows

$$
\begin{aligned}
& \ln \left\{\frac{[\mathrm{M}]_{0}}{[\mathrm{M}]_{\mathrm{t}}}\right\}=\left(\frac{k_{\mathrm{p}}+k_{\mathrm{trm}}}{k_{\mathrm{t}}}\right)[\mathrm{C}]_{0}\left\{1-\exp \left(-k_{\mathrm{t}} \cdot t\right)\right\} \\
& \ln \left\{\frac{[\mathrm{M}]_{0}}{[\mathrm{M}]_{\infty}}\right\}=\left(\frac{k_{\mathrm{p}}+k_{\mathrm{trm}}}{k_{\mathrm{t}}}\right)[\mathrm{C}]_{0}
\end{aligned}
$$

where $k_{\mathrm{p}}, k_{\mathrm{trm}}$ and $k_{\mathrm{t}}$ are rate constants for propagation, chain transfer to monomer and termination reactions, respectively. $[C]_{0}$ and $[\mathrm{M}]_{0}$ represent initial catalyst and initial monomer concentrations, respectively, and $[M]_{t}$ and $[M]_{\infty}$ denote the unchanged monomer concentrations in the contents at the given time $t$ and at infinite time $t=\infty$, respectively.

Equations 1 and 2 provide a good description of all experimental results. Therefore, the individual rate constants for the polymerization can be determined by Pepper's treatment. The ratio of rate constants

$$
\frac{k_{\mathrm{p}}+k_{\mathrm{trm}}}{k_{\mathrm{t}}}=9.97 l / \mathrm{mol}
$$

may be derived from the slope of the straight line in Figure 3. Substituting this value in eq 1, we obtain the value of $k_{\mathrm{t}}$ by trial and error. Thus a single time constant, $4.1 \times 10^{-4} \mathrm{sec}^{-1}$, describes all the rate results at $0^{\circ} \mathrm{C}$.

The number-average degree of polymerization, $\bar{P}_{n}$, may be represented as

$$
\frac{1}{\bar{P}_{n}}=\frac{k_{\mathrm{trm}}}{k_{\mathrm{p}}+k_{\mathrm{trm}}}+\frac{[\mathrm{C}]_{0}}{[\mathrm{M}]_{0} X_{\infty}}
$$

Figure 4 shows a plot of polymerization degree $v s$. the final conversion. The intercept of the straight line gives the value of

$$
\frac{k_{\mathrm{trm}}}{k_{\mathrm{p}}+k_{\mathrm{trm}}}=0.098
$$

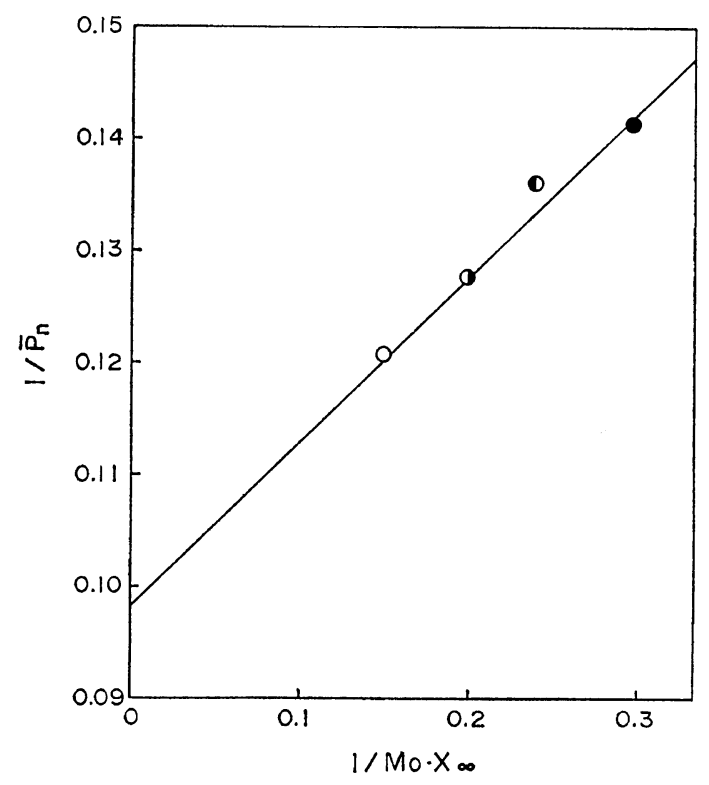

Figure 4. Relationship between the polymerization degree and the final conversion: Temp, $0^{\circ} \mathrm{C} ;[\mathrm{HCl}]=$ $0.116 \mathrm{~mol} / l ;\left[\mathrm{H}_{2} \mathrm{O}\right]=0.437 \mathrm{~mol} / l ;[\mathrm{AOM}]=10.84(\mathrm{O})$, $8.13(\odot), 6.77(\mathrm{O})$, and $5.42(\bullet) \mathrm{mol} / l$.

Consequently, the individual rate constants are calculated as follows.

$$
\begin{aligned}
k_{\mathrm{p}} & =3.69 \times 10^{-3} l / \mathrm{mol} \mathrm{sec} \\
k_{\mathrm{trm}} & =4.01 \times 10^{-4} l / \mathrm{mol} \mathrm{sec} \\
k_{\mathrm{t}} & =4.10 \times 10^{-4} \mathrm{sec}^{-1}
\end{aligned}
$$

The value of chain-transfer constant $\left(k_{\mathrm{trm}} / k_{\mathrm{p}}\right)$ is 
Table II. Temperature dependence of rate constants $^{\mathrm{a}}$

\begin{tabular}{cc}
\hline $\begin{array}{c}\text { Polymerization } \\
\text { temperature, }\end{array}{ }^{\circ} \mathrm{C}$ & $\frac{k_{\mathrm{p}}+k_{\mathrm{trm}}}{k_{\mathrm{t}}}$ \\
\hline 0 & 9.97 \\
20 & 10.80 \\
40 & 13.29 \\
\hline
\end{tabular}

a This polymerization was carried out with [AOM] $=6.77,[\mathrm{HCl}]=0.058$ and $\left[\mathrm{H}_{2} \mathrm{O}\right]=0.218 \mathrm{~mol} / l$.

considerably large (ca. 0.1 ), and hence it is understandable that the chain-transfer reaction should determine the molecular weights.

Table II indicates the temperature dependence of the ratio of rate constants for the polymerization with $[\mathrm{M}]_{0}=6.67 \mathrm{~mol} / l$ and $[C]_{0}=0.058 \mathrm{~mol} / l$. Though an Arrhenius plot gives a straight line with a slope corresponding to $1.88 \mathrm{kcal} / \mathrm{mol}$, the slope does not correspond to the activation energy for the polymerization. The fact of the negative slope illustrates that the temperature affects propagation and/or chain transfer rather than termination reactions.

\section{Chemical Structure of PAOM}

The resulting polymer is a hygroscopic powder, and readily soluble in water and partly soluble in dimethylformamide. On the other hand, PAOM obtained by the thermal and butyllithium-catalyzed polymerizations is soluble in both acidic and basic aqueous solutions and insoluble in water. ${ }^{2}$ Thus solubility in water may be dependent on the content of pendant oxime group in the polymer.

For the case in which AOM is added to the growing cation, the two resonating forms, shown in eq 4 , give rise to two possible structures of resulting chain unit; 1,2-addition, with a pendant oxime group; or 1, 4-addition, with a double bond in the chain.<smiles>CC[C+]C=NO</smiles>

3, 4-Addition, with a pendant vinyl group, is unlikely to occur owing to the instability of the resulting cation and the steric hindrance. The relative amounts of the respective structure of the chain unit can be determined by chemical means. ${ }^{2}$ The analytical values obtained are summarized in Table III. As can be seen from the Table, PAOM obtained by the cationic polymerization contains $73.8 \%$ of the structural unit having a pendant oxime group per unit, $14.6 \%$ of those having a carbon-carbon double bond per unit and $11.6 \%$ of unknown structural units. This finding indicates that 1,2-addition is the predominant reaction in the cationic polymerization, as opposed to that in thermal and BuLi-catalyzed polymerizations.

Equations 5 and 6 show a chain-transfer reaction with AOM. Equation 5 indicates the conventional chain-transfer reaction, and acrolein oxime cation formed by the reaction may reinitiate the polymerization. Equation 6 shows that the resultant PAOM contains $\mathrm{CH}_{2}=\mathrm{CH}-\mathrm{CH}=\mathrm{N}-\mathrm{O}-$ as its terminal unit.

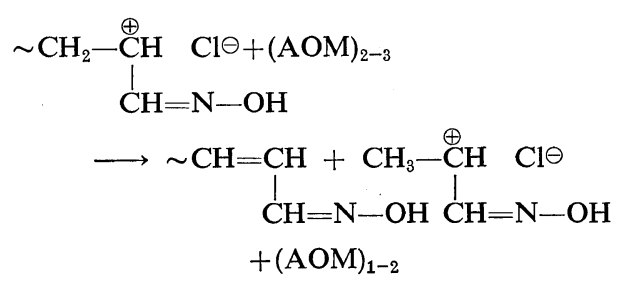

Table III. Characteristics of PAOM

\begin{tabular}{|c|c|c|c|c|c|c|}
\hline \multicolumn{4}{|c|}{ Polymerization conditions } & \multirow[b]{2}{*}{$\mathrm{MW}^{\mathrm{a}}$} & \multirow{2}{*}{$\begin{array}{c}\mathrm{C}=\mathrm{C} \\
\text { bond }^{\mathrm{b}}, \\
\%^{\circ}\end{array}$} & \multirow{2}{*}{$\begin{array}{c}\text { Oxime } \\
\text { group }^{\mathrm{c}},\end{array}$} \\
\hline$\underset{\mathrm{mol} / \mathrm{l}]}{[\mathrm{AOM}]}$ & $\begin{array}{c}\text { [Catalyst] } \\
\mathrm{mol} / l\end{array}$ & Solvent & $\underset{{ }^{\circ} \mathrm{C}}{\text { Temp, }}$ & & & \\
\hline 8.13 & $\mathrm{HCl}^{\mathrm{d}}, \quad 0.116$ & DCE & 0 & 556 & 14.6 & 73.8 \\
\hline $8.13^{e}$ & BuLi, $\quad 0.0452$ & DCE & 30 & 660 & 48.4 & 44.8 \\
\hline $13.74^{\mathrm{f}}$ & None & None & 60 & 2100 & 42.0 & 46.0 \\
\hline
\end{tabular}

${ }^{\mathrm{a}} \mathrm{MW}$, molecular weight. ${ }^{\mathrm{b}} \%$ of structural units having a carbon-carbon double bond per unit. $\mathrm{c} \%$ of structural units having a pendant oxime group per unit. ${ }^{a}$ Concentrated hydrochloric acid is used. ${ }^{e}$ ref 8. ${ }^{\mathrm{f}}$ ref 2 . 


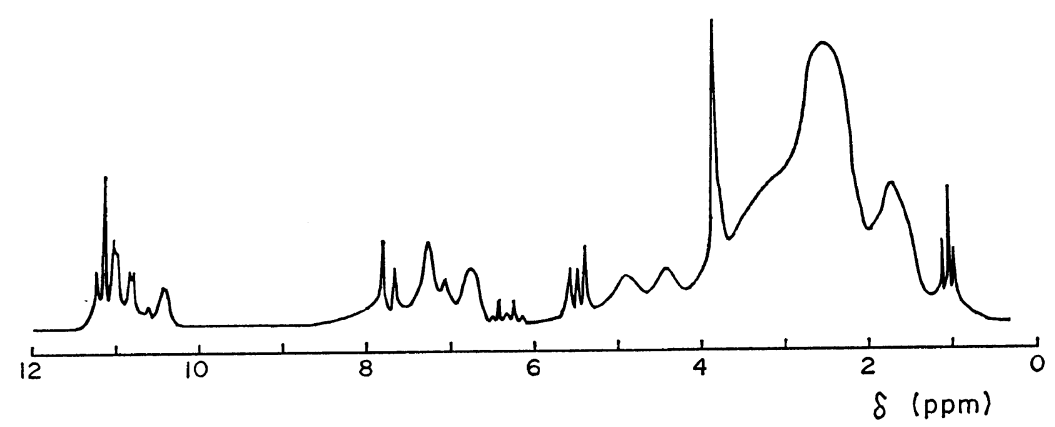

Figure 5. NMR spectrum of PAOM: Solvent, DMSO- $d_{6}$; internal standard, TMS; temp, $24^{\circ} \mathrm{C}$; concn, $9.6 \%(\mathrm{w} / \mathrm{v})$.<smiles>CC[C+]C=NO</smiles><smiles>C=CC=CN(O)[O+](Cl)N=CC=C</smiles>

$$
+(\mathrm{AOM})_{1-2}
$$$$
\begin{gathered}
\stackrel{+(\mathrm{AOM})_{2}-3}{\longrightarrow} \sim \mathrm{CH}_{2}-\mathrm{CH}-\mathrm{O}-\mathrm{N}=\mathrm{CH}-\mathrm{CH}=\mathrm{CH}_{2} \\
\stackrel{\mathrm{C}}{\mathrm{H}}=\mathrm{N}-\mathrm{OH}
\end{gathered}
$$$$
\begin{aligned}
+\mathrm{CH}_{3}-\stackrel{\oplus}{\mathrm{C}} \mathrm{H} \quad \mathrm{Cl} \ominus+(\mathrm{AOM})_{1-2} \\
\stackrel{\mathrm{C}}{\mathrm{H}}=\mathrm{N}-\mathrm{OH}
\end{aligned}
$$

By a rough estimation, it is found that there are one or two carbon-carbon double bond units per polymer. Some of the double bonds may be located at the chain end. This fact is confirmed by NMR spectroscopy; as shown in Figure 5, the spectrum of PAOM has peaks at 7.71, 7.04, 6.40, and $5.50 \mathrm{ppm}$ assigned to the protons of the end group $\mathrm{CH}_{2}=\mathrm{CH}-\mathrm{CH}=$. These assignments were referred to in our previous paper. ${ }^{5}$ Moreover, the peak at $1.05 \mathrm{ppm}$ indicates that PAOM contains a methyl group at its other end. Peaks at $7.30,6.80$ and 3.85 ppm may be assigned to protons of pendant oxime, $-\mathrm{CH}=\mathrm{N}-$, of syn and anti forms, and $-\mathrm{C}-\mathrm{CH}_{2}-\mathrm{O}-$ linkage in the backbone of the polymer, respectively.

Hydrochloric acid and the polymer cation are likely to attack carbon-carbon double bonds in the polymer chain or in the terminal vinyl group and the resulting structures of the chain unit should be considered as unknown. Termination involves combination with counter anion (eq 7) or production of a stable iminium ion (eq 8). The latter may also form structural units having carboncarbon double bond in the chain ending.<smiles>CC[C+]C=NO</smiles><smiles>CC[C+]C=NO</smiles>

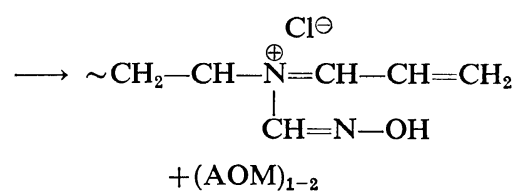

\section{REFERENCES}

1. Y. Toi and Y. Hachihama, Kogyo Kagaku Zasshi (J. Chem. Soc. Jpn., Ind. Chem. Sect.), 64, 595 (1961).

2. S. Masuda and T. Ota, Polym. J., 9, 459 (1977).

3. S. Masuda and T. Ota, Kobunshi Ronbunshu 31, 61 (1974).

4. R. E. Burton and D. C. Pepper, Proc. R. Soc. London, Ser. A, 263, 58 (1961).

5. S. Masuda, H. Kihara, and T. Ota, Nippon Kagaku Kaishi (J. Chem. Soc. Jpn.), 608 (1974).

6. I. P. Losev and O. Ya Fedotova, "Praktikum po Khimii Vysokopolymernykh Soedinii," Gosudarstvennoe Nauchno-Tekhnicheskoe Iedatelistvo Khimicheskoi Literatur, Japanese translation, Gihōdō, Tōkyo, 1965, p 67.

7. D. D. Van Slyke, Ber., 43, 3170 (1910).

8. S. Masuda, M. Tanaka, and T. Ota, Polym. J., 10, 387 (1978). 


\section{S. MASUdA and T. Ota}

9. S. Masuda, M. Torii, and T. Ota, unpublished data.

10. M. J. Hayse and D. C. Pepper, Proc. R. Soc.
London, Ser. A, 263, 63 (1961).

11. K. Ikeda, T. Higashimura, and S. Okamura, Kobunshi Kagaku, 26, 364 (1969). 